\title{
Comparison of Interstitial Fluid pH, PCO2, PO2 with Venous Blood Values During Repetitive Handgrip Exercise
}

Babs R. Soller, Michael Shear, Matthias Walz, Michelle Landry, Stephen Heard, R. Donald Hagan, FACSM, Department of Anesthesiology, UMass Medical School, Worcester, MA and NASA Johnson Space Center, Houston, TX

We evaluated the use of a small, fiber optic sensor to measure $\mathrm{pH}, \mathrm{PCO}_{2}$ and $\mathrm{PO}_{2}$ from forearm muscle interstitial fluid (IF) during handgrip dynamometry. PURPOSE:

Compare $\mathrm{pH}, \mathrm{PCO}_{2}$ and $\mathrm{PO}_{2}$ values obtained from venous blood with those from the IF of the flexor digitorum superficialis (FDS) during three levels of exercise intensity.

METHODS: Six subjects $(5 \mathrm{M} / 1 \mathrm{~F})$, average age $29 \pm 5 \mathrm{yrs}$, participated in the study. A venous catheter was placed in the retrograde direction in the antecubital space and a fiber optic sensor (Paratrend, Diametrics Medical, Inc.) was placed through a $22 \mathrm{G}$ catheter into the FDS muscle under ultrasound guidance. After a 45 min rest period, subjects performed three 5-min bouts of repetitive handgrip exercise (2s contraction/ $1 \mathrm{~s}$ relaxation) at attempted levels of $15 \%, 30 \%$ and $45 \%$ of maximal voluntary contraction. The order of the exercise bouts was random with the second and third bouts started after blood lactate had returned to baseline. Venous blood was sampled every minute during exercise and analyzed with an I-Stat CG-4+ cartridge, while IF fiber optic sensor measurements were obtained every $2 \mathrm{~s}$. Change from pre-exercise baseline to end of exercise was computed for $\mathrm{pH}, \mathrm{PCO}_{2}$ and $\mathrm{PO}_{2}$. Blood and IF values were compared with a paired t-test. RESULTS: Baseline values for $\mathrm{pH}, \mathrm{PCO}_{2}$ and $\mathrm{PO}_{2}$ were $7.37 \pm 0.02$, $46 \pm 4 \mathrm{~mm} \mathrm{Hg}$, and $36 \pm 6 \mathrm{~mm} \mathrm{Hg}$ respectively in blood and $7.39 \pm 0.02,44 \pm 6 \mathrm{~mm} \mathrm{Hg}$, and $35 \pm 14 \mathrm{~mm} \mathrm{Hg}$ in IF. Average changes over all exercise levels are noted in the Table below. For each parameter the exercise-induced change was at least twice as great in IF as in blood. In blood and IF, $\mathrm{pH}$ and $\mathrm{PCO}_{2}$ increases were directly related to exercise intensity. Change in venous $\mathrm{PO}_{2}$ was unrelated to exercise intensity, while IF $\mathrm{PO}_{2}$ decreased with increases in exercise intensity. CONCLUSIONS: Measurement of IF $\mathrm{pH}, \mathrm{PCO}_{2}$ and $\mathrm{PO}_{2}$ is more sensitive to exercise intensity than measurement of the same parameters in venous blood and provides continuous assessment during and after exercise.

Funded by the National Space Biomedical Research Institute through NASA NCC 9-58.

\section{Average change in parameter from baseline to end exercise}

\begin{tabular}{r|c|c|c|}
\multicolumn{1}{r}{} & \multicolumn{1}{c}{$\mathbf{p H}^{*}$} & $\mathbf{P C O}_{2}{ }^{*}(\mathbf{m m ~ H g})$ & $\mathbf{P O}_{2}{ }^{*}(\mathbf{m m ~ H g})$ \\
\cline { 2 - 4 } venous blood & $-0.10 \pm 0.06$ & $20 \pm 11$ & $-10 \pm 6$ \\
\cline { 2 - 4 } Interstitial fluid & $-0.22 \pm 0.18$ & $50 \pm 42$ & $-21 \pm 12$ \\
\cline { 2 - 4 } & &
\end{tabular}

${ }^{*} p<0.05$ venous compared to IF 